\title{
Per 50 High Powered Fields
}

National Cancer Institute

\section{Source}

National Cancer Institute. Per 50 High Powered Fields. NCI Thesaurus. Code C158698.

A unit of measurement of the number of entities per unit of area equal to fifty high powered fields. 